\title{
Authentic leadership practices informed by a rural hospital study
}

\author{
Roseanne Fairchild *, Shiaw-Fen Ferng, Randi Zwerner \\ Indiana State University, College of Nursing, Health, and Human Services, Terre Haute, Indiana, USA
}

Received: December 29, 2014

Accepted: March 2, 2015

Online Published: March 10, 2015

DOI: $10.5430 /$ jha.v4n2p54

URL: http://dx.doi.org/10.5430/jha.v4n2p54

\begin{abstract}
The purpose of this study was to explore perceptions of work environment characteristics across employee groups in a rural hospital to determine if authentic leadership and management practices were perceived to be actualized in the organization. Creating a healthy work environment through authentic leadership practices is critical to sustaining care quality improvements (QIs) and patient safety. In light of fewer financial and educational resources, an academic-practice partnership provides evidencebased support for administrators in rural hospitals. This mixed methods study involved the following measures: 1) Descriptive cross-sectional survey of hospital employees regarding work environment characteristics $(\mathrm{N}=139 / 188$; 74\% response rate), yielding statistical power of .95 , and 2) multiple qualitative focus groups with employees $(\mathrm{N}=37)$ to explore contextual factors potentially influencing perceptions of work environment. There were statistically significant differences among perceived levels of vitality for hospital administrative staff compared to clinical and ancillary staff $(p<.000-p<.026)$. Thematic content of qualitative data revealed issues regarding a perceived lack of authentic leadership and management behaviors. Adopting best practices related to QIs may first require a paradigm shift by hospital leadership and management through conscious promotion of mutual trust and healthy work behaviors. An academic-practice partnership can provide data-based insights into work environment characteristics that may need attention so that the hospital administrator may empower staff-driven, collaborative QIs from an evidence-based stance.
\end{abstract}

Key Words: Rural hospital, Healthy work environment, Authentic leadership, Employee vitality, Mixed methods

\section{Introduction}

There has been a call globally for hospital administrators and care providers working in rural hospitals to collaboratively form rural networks, adopt best practices based on clinical guidelines driven by current evidence, and create new programs to motivate rural populations to achieve improved health status. ${ }^{[1-3]}$ Expert recommendations encourage both within-hospital and across-hospital collaborations and quality improvements (QIs) so that providers and administrators working in smaller, low volume rural hospitals can share new knowledge and promote evidence-based prac- tice in rural and remote healthcare delivery. ${ }^{[1-4]}$

While a few predominantly rural regions globally have wellorganized rural hospital networks to assist them in becoming prepared to promote evidence-based practice in care quality and safety, ${ }^{[2,5-9]}$ hospital administrators in remote rural hospitals that are not part of an integrative health system may benefit from working collaboratively within an academicpractice partnership to help generate ideas to collectively enhance quality of care delivery. ${ }^{[10-13]}$ From a practical operational standpoint, how might hospital leadership, management and departmental/unit staff in a "standalone" ru-

*Correspondence: Roseanne Fairchild; Email: roseanne.fairchild@indstate.edu; Address: Indiana State University, 1433 N. $6 \frac{1}{2}$ Street, Landsbaum Center for Health Education, College of Nursing, Health, and Human Services, Terre Haute, Indiana 47807, USA. 
ral hospital respond to an exploratory case study involving assessment of the healthy work environment characteristics reported to be necessary to support robust potential for successful QIs ${ }^{[1-5]}$ ?

To lay groundwork for the study, the study team and the hospital's top leadership and management teams have worked within an academic-practice partnership for three contiguous years involving needs-based service learning projects in health information technology applications and in healthcare leadership and management. ${ }^{[13,14]}$ The purpose of this follow-up study was to assess and evaluate the potential presence of authentic leadership practices among hospital leadership and management teams to support a healthy work environment for hospital employees. A healthy work environment promotes optimal employer-employee relationships, and thus the ability to focus efforts on patientcentered, enhanced quality of care. ${ }^{[15,16]}$

\section{Theoretical framework}

According to healthcare experts, a hospital needs to be a patient-centered organization where patients and providers are true partners in care decisions. ${ }^{[3,15-18]}$ The role of the hospital administrator embodies a leader who is responsible for ensuring a patient-centered focus, and developing processes to 1) promote evidence-based care and patient engagement, 2) report on quality and cost, and 3) supervise care. ${ }^{[1,3,15,17,18]}$ With these elements in mind, the Robert Wood Johnson Foundation's Transforming Care at the Bedside $(\mathrm{TCAB})^{[15]}$ model (see Table 1) was chosen as the framework for the study.

According to the Institute for Healthcare Improvement, ${ }^{[15]}$ transformational leadership is defined as being able to establish, communicate and oversee QIs with employees at all levels of an organization. However, while the framework includes this definition of transformational leadership as an administrative imperative, the set of TCAB principles does not provide explicit explanatory content or an actual set of leader behaviors that a healthcare administrator who strives to be transformational can embrace and work to follow. In order for an administrator to engage in realistic selfassessment, the authors observed that the concept of authentic leadership as defined by the American Association for Critical Care Nurses (AACN) ${ }^{[16]}$ in relationship to creating a healthy work environment would provide a concrete definition and a set of leader behaviors needed to promote selfactualization as a transformational leader.

Table 1: Transforming Care at the Bedside: key quality parameters*

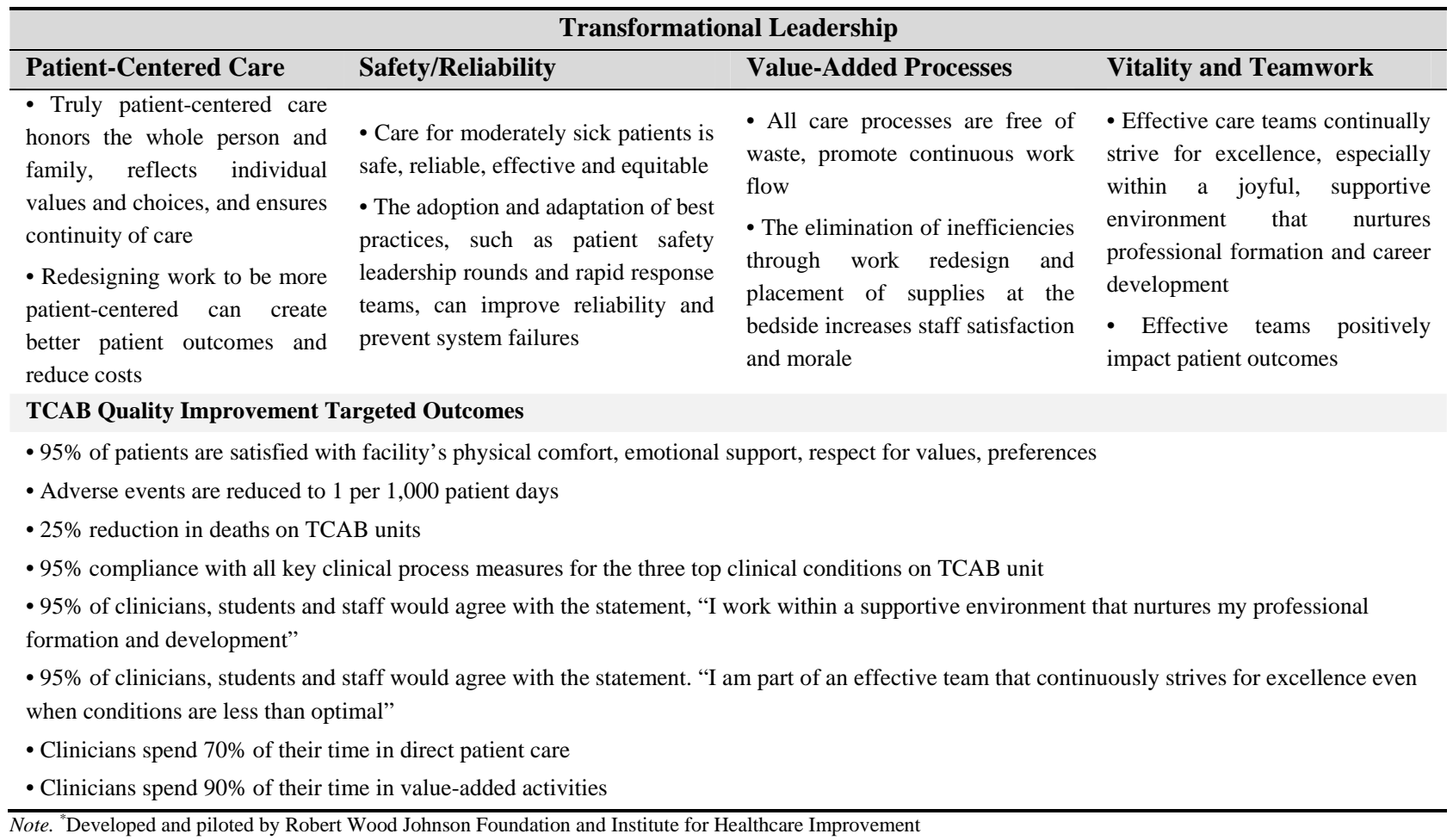

According the AACN, ${ }^{[16]}$ authentic leadership is defined as the administrator's “... obligation to establish, maintain and improve healthcare environments and employment conditions conducive to providing quality care consistent with the

values of the healthcare professions, and to maintain compassionate and caring relationships with a commitment to fair treatment of individuals and integrity-preserving compromise" ( $p$. 11). Therefore, the evidence-based set of au- 
thentic leader behaviors as defined by $\mathrm{AACN}^{[16]}$ can help to operationalize the concept of transformational leadership to support a healthy work environment and the high quality QI outcomes proposed as part of the TCAB model. The work of an authentic, transformational leader inspires an atmosphere conducive to trust and mutual respect and, in turn, can enhance the overall commitment of employees. ${ }^{[15,16]}$

The $\mathrm{TCAB}^{[15]}$ model promotes ongoing evaluation of healthcare leadership practices and work environment characteristics through utilization of a 10-item socio-behavioral "Vitality" instrument. ${ }^{[19,20]}$ The instrument is currently being tested and is reported to support measurement of five major principles proposed to promote quality of care delivery: Patient-centered care, patient safety, value-added care, employee vitality, and transformational leadership (see Table 1). ${ }^{[15,19,20]}$

The current study was launched with the knowledge that hospital administrators wanted to reduce turnover by improving overall vitality of hospital employees. Nursing unit administrators, in particular, also desired to create an atmosphere more amenable to generating nursing unit employee "buy-in" and eventual success for targeted QI activities. An initial leadership team meeting and pre-survey with hospital administrators re-confirmed these goals, as advised in the TCAB toolkit. ${ }^{[15]}$

\section{Ethical considerations}

The study was planned collaboratively with the rural hospital's top leadership team (refer to Table 2) and was approved by the sponsoring university's institutional review board (IRB). Informed consent was provided to the potential participants and there were no direct incentives for participating in the study. Study data were collected during Winter 2012 - 2013 and were recorded and analyzed in the aggregate to maintain the anonymity of the participants. Data collection records were maintained according IRB standards for security and confidentiality.

\section{Methodology}

A mixed methods approach involving both quantitative and qualitative data collection and analysis was utilized for this study. This approach is viewed as combining complementary methodologies to stimulate new insights and research questions (initiation), test the consistency of findings obtained through different instruments (triangulation), and provide richness and greater detail to a study (expansion). ${ }^{[21]}$ To promote enhanced understanding, the qualitative narratives provided rich context for the quantitative statistical results.

\subsection{Quantitative methods}

\subsubsection{Vitality survey}

An online 10-item, Likert-type survey measuring perceptions of vitality was distributed via secure email link to fulltime and part-time staff, management and leadership $(\mathrm{N}=$ 188). Upon accessing the survey, the participants were presented with an informed consent statement regarding strict confidentiality of the survey, and reporting of data in anonymous, aggregate form only. From this page, participants could choose either "Accept", and move on to the survey items, or "Do not accept" and opt out of the survey. For each positively-worded survey item, participants were asked to rate perceptions of hospital leadership, work environment, and working relationships using a 5-point scale from "strongly agree" to "strongly disagree".

\subsubsection{Statistical analysis}

With sample size of 188 and using a 5\% margin of error, a minimum sample of $\mathrm{N}=126$ was needed to achieve statistical power of 95. A total of 157 employees accessed the Vitality survey, with 18 sets of survey responses discarded due to partial completion/missing data, resulting in a $74 \%$ response rate achieved for the study $(\mathrm{N}=139 / 188)$. Therefore, sample size reflected statistical power of .95. Quantitative data were analyzed for descriptive and correlational results using SPSS 20.0 statistical software. ${ }^{[22] ~ S t a t i s t i c a l ~}$ significance was set at $p<.05$. Internal consistency reliability for the survey instrument was .88 .

One-way analysis of variance (ANOVA) was utilized to determine any statistically significant differences among individual vitality survey ${ }^{[15]}$ items across groups of employees. The Bonferroni post-hoc test was utilized to identify potential differences between specific groups of employees. To delineate among the groups, administrative staff included hospital administrators, administrative assistants and managers; clinical staff included physicians employed by the hospital, as well as nurses, nursing assistants, and therapists; ancillary staff included information technology, environmental, janitorial and food services employees (see Table 2).

\subsection{Qualitative methods}

\subsubsection{Focus group format}

For the qualitative portion of the study, multiple focus groups were conducted using a guided discussion template with two open-ended questions, asking the participants to describe aspects of both good and bad patient care experiences on their unit. Subsequent probing questions such as "Can you tell us more about that?" or "How do you believe [action] impacted care?" were utilized to expand the discussion of both types of patient care stories. The discussions were led by the two co-investigators and a research assistant 
recorder for each session. To create a representative sample for data collection $(\mathrm{N}=37)$, the focus groups engaged employees in staff, management and leadership roles representing all hospital units and departments in open discussion during eight sessions, across three shifts, over a four-week period.

Focus group participation was voluntary and comprised of 3-7 employees per session, with employee and supervisor focus groups conducted separately to promote open, frank discussion. The discussion of patient care experiences was emphasized to support revelations concerning any and all actions (or lack thereof) that were perceived to be connected to patient care outcomes. Pseudonyms were assigned to discussion participants so that their contributions would remain anonymous for reporting purposes.

\subsubsection{Qualitative data analysis processes}

Upon completion of each focus group session, and at the end of the final session, the narrative data were collected and evaluated for categories and sub-categories of related thematic content by the study team utilizing naturalistic inquiry. ${ }^{[23]}$ Naturalistic inquiry as a qualitative framework emphasizes collection and analysis of data in the natural setting where people live and work on a daily basis. ${ }^{[23]}$ Constant comparative analysis ${ }^{[23]}$ of the data allowed the research team to subsequently inductively assess, code and categorize the words and phrases used by the group participants as they reported their unit and departmental patient care stories in detail. The study team worked to maintain a neutral stance as the data were evaluated, and acknowledge that their background in nursing and epidemiology were the lenses through which the patient care stories were viewed.

Qualitative themes emerged inductively based on coding and saturation of the narrative data, providing a naturalistic context for the quantitative results of the study. ${ }^{[23]}$ An experienced doctoral level qualitative researcher was asked to audit the narrative data to verify saturated themes as reported for the study. Based on the auditor's recommendations, data-based sub-themes were also suggested and are reported for the study.

Table 2: Distribution of employee participants

\begin{tabular}{|c|c|c|}
\hline Clinical (n) & Administrative (n) $^{*}$ & Ancillary (n) ${ }^{*}$ \\
\hline \multicolumn{3}{|l|}{ Nursing Assistant (6) } \\
\hline Registered nurse (39) & Assistant Manager (3) & \multirow{6}{*}{$\begin{array}{l}\text { Other (60) } \\
\text { (Maintenance employees; Food service employees; } \\
\text { IT employees; ancillary services/workout facility } \\
\text { staff) }\end{array}$} \\
\hline Licensed practical nurse (1) & Manager (15) & \\
\hline Radiology technician (1) & Administrative Assistant/Unit Secretary (7) & \\
\hline Respiratory therapist (3) & Administrator (e.g., DON, CNO, CFO, COO, & \\
\hline Physician (2) & CEO, VP) (6) & \\
\hline \multicolumn{2}{|l|}{ Pharmacist (1) } & \\
\hline Total $53(50)^{* *}$ & $31^{* *}$ & $60(58)^{* *}$ \\
\hline
\end{tabular}

\section{Results}

\subsection{Quantitative}

Based on the ANOVA analyses, self-reported levels of vitality across three employee groups revealed administrative employees reported the highest levels of vitality based on the maximum composite score of $50(\bar{x}=38.7 ; S D=4.8 ; \mathrm{n}$ $=31 ;)$ compared to ancillary staff $(\bar{x}=34.7 ; S D=8.9 ; \mathrm{n}=$ $58)$ and clinical staff $(\bar{x}=38.2 ; S D=7.9 ; \mathrm{n}=50)$. The difference in composite vitality score between administrative and ancillary employees was statistically significant $(p=.026)$. Table 3 shows distribution of individual vitality items and composite vitality scores.

The statistical analyses also revealed that certain aspects of vitality for hospital administrative staff were statistically significantly higher than for ancillary and clinical staff $(p$ $<.000-p<.026$ ) (see Table 3). A low-scoring item for clinical and ancillary staff reflected a lack of administrator behaviors perceived as authentic leader behaviors, namely a perceived lack of interest in staff ideas $(p<.001)$. However, the majority of clinical and ancillary staff reported that they would speak up about a patient safety concern $(p<.014)$.

Also in relation to patient care delivery, a majority of clinical and ancillary staff reported a lack of teamwork $(p<.000)$, and loss of important patient care information across different units and departments during patient handovers $(p<.000)$. In contrast, high-scoring items for employee groups involved easy access to supplies and equipment, adequate support services, and good teamwork within one's own unit.

Overall, in addition to selected positive perceptions of the work environment revealed in these data, the reported differences in 1) management and staff perceptions of employee morale, 2) employees' perceptions of a lack of authentic leader behaviors among nurse administrators, and 3) statistically significant differences in levels of vitality across hospital employees, needed to be considered when planning for QIs as a follow-up to this study. While employee perceptions of leader behaviors were not consistently positive, 
it was a credit to leadership and management that the employees would speak up if there was a patient safety concern. Awareness of patient safety has been associated with a positive safety culture, and therefore improved patient health outcomes, on hospital nursing units. ${ }^{[19,24]}$ Moreover, care needed to be taken to communicate to both administrators and employees that 2-way communication and mutually beneficial accountabilities between management and staff would need to be emphasized with any type of QI-based follow-up study or health services project.

Table 3: Vitality scale results for rural hospital employees

\begin{tabular}{|c|c|c|c|c|c|c|c|c|c|}
\hline \multirow{2}{*}{ Item } & \multirow{2}{*}{ Vitality Scale } & \multicolumn{5}{|c|}{$\begin{array}{l}\text { Likert Scale Items (\% Respondents) } \\
\text { (Low [1] to High [5] Score) }\end{array}$} & \multicolumn{3}{|c|}{ ANOVA $(N=139)$} \\
\hline & & 1 & 2 & 3 & 4 & 5 & Mean $\pm S D$ & $\alpha^{*}$ & $\begin{array}{l}\text { Multiple } \\
\text { Comparisons }^{* *}\end{array}$ \\
\hline 1 & $\begin{array}{l}\text { I have easy access to the supplies and } \\
\text { equipment I need to do my work on my } \\
\text { unit / in my department. }\end{array}$ & 2.8 & 8.5 & 2.1 & 42.3 & 44.3 & $4.2 \pm 1.0$ & .442 & \\
\hline 2 & $\begin{array}{l}\text { The support services for my unit / } \\
\text { department respond in a timely way. }\end{array}$ & 1.4 & 8.5 & 12.8 & 46.1 & 31.2 & $4.0 \pm 1.0$ & $.015^{*}$ & AD:AN; AD:CL \\
\hline 3 & $\begin{array}{l}\text { I can discuss challenging issues with team } \\
\text { members on my unit / in my department. }\end{array}$ & 3.5 & 4.3 & 15.6 & 41.1 & 35.5 & $4.0 \pm 1.0$ & .254 & \\
\hline 4 & $\begin{array}{l}\text { My ideas really seem to count on my unit / } \\
\text { in my department. }\end{array}$ & 5.6 & 14.1 & 28.2 & 29.6 & 22.5 & $3.5 \pm 1.1$ & $.006^{*}$ & AD:AN; AD:CL \\
\hline 5 & $\begin{array}{l}\text { I speak up if I have a patient safety } \\
\text { concern. }\end{array}$ & 1.4 & 1.4 & 8.1 & 36.2 & 52.9 & $4.4 \pm 0.8$ & $.014^{*}$ & CL:AN \\
\hline 6 & $\begin{array}{l}\text { Care team members on my unit / in my } \\
\text { department feel free to question the } \\
\text { decisions or actions of those with more } \\
\text { authority. }\end{array}$ & 6.5 & 11.6 & 28.3 & 39.1 & 14.5 & $3.5 \pm 1.1$ & .092 & \\
\hline 7 & $\begin{array}{l}\text { Important patient care information is } \\
\text { exchanged by care providers during shift } \\
\text { changes. }\end{array}$ & 0.8 & 5.4 & 36.4 & 37.2 & 20.2 & $3.7 \pm 0.9$ & $.000^{*}$ & AD:CL; AN:CL \\
\hline 8 & $\begin{array}{l}\text { If I have an idea about how to make things } \\
\text { better on this unit /in this department, } \\
\text { management and other staff are willing to } \\
\text { try it. }\end{array}$ & 5.0 & 13.7 & 23.0 & 46.0 & 12.2 & $3.5 \pm 1.0$ & .111 & \\
\hline 9 & $\begin{array}{l}\text { Care professionals communicate complete } \\
\text { patient information during patient } \\
\text { hand-offs and care transitions. }\end{array}$ & 0.0 & 3.9 & 43.3 & 37.0 & 15.7 & $3.7 \pm 0.8$ & $.000^{*}$ & AD:CL; AN:CL \\
\hline \multirow{4}{*}{10} & Vitality Scale composite score $=50$ & & & & & & $36.9 \pm 7.9$ & $.026^{*}$ & AD:AN \\
\hline & Administrative $(\mathrm{n}=31)$ & & & & & & $38.7 \pm 4.8$ & & \\
\hline & Clinical $(n=50)$ & & & & & & $38.2 \pm 7.9$ & & \\
\hline & Ancillary $(\mathrm{n}=58)$ & & & & & & $34.7 \pm 8.9$ & & \\
\hline
\end{tabular}

\subsection{Qualitative}

Focus group comments revealed a rich mix of narrative stories regarding patient experiences and hospital work environment that were communicated and shared during sessions 1-2 hours in length. Narrative data categories that were saturated and representative of broad themes (headings) and sub-themes included both positive and negative perceptions of patient care, hospital management and leadership, and hospital work environment. Based on the- matic content, participants discussed patient care stories ultimately reflecting positive-negative polarities of the set of TCAB principles: ${ }^{[15]}$

\subsubsection{Patient-centeredness}

One nurse stated that "Everybody knows everybody, this means we can give better care"; a nursing assistant agreed, "We really care about our patients, we often know them"; a unit sec- 
retary added: "We go the extra mile, we have collected money for people when they need it. And I have seen the nurses caring for patients and families - they always follow-up to be sure they [patients] have what they need"; however, one hospital administrator alternatively observed: "We have Ebsco Host online for the nurses, but they don't seem to take advantage of this for patient teaching and discharge."

The positive relational phenomenon of knowing one's patients has been reported by care providers in other rural care settings. ${ }^{[11,12,25]}$ This sub-theme was reflective of multiple patient care stories participants related as primarily supportive of the overall theme, "patient-centered care". However, one hospital administrator's observation that new online resources were not being utilized consistently by nursing unit staff was similar to research utilization results in other studies of rural nurse providers. Healthcare experts have reported that rural staff nurses need supplemental experiences to seamlessly engage in evidence-based practice (EBP), since particular cases may not be seen as frequently as in urban hospital setting. Formal support by a staff educator or an academic partner was encouraged to promote consistent application of new EBP tools in practice. ${ }^{[11,12,25]}$

\subsubsection{Teamwork}

A staff nurse noted "We have a high level of service and personal attention because we work together"; and an employee in environmental services stated, "I think most staff works together well; you'll always have a few that don't, but I think most of us do"; another nurse explained, "We keep families up-to-date on what's going on." In contrast, a nurse administrator observed, "You know, I make rounds on units once a month. I also hold meetings so that unit staff can have input whenever we are going to change something, but no one ever comes. I just don't know what will work to help the situation."

The importance of teamwork and its impact on quality of care on hospital units has been welldocumented, ${ }^{[1,15,16,19,26]}$ and patient stories the participants shared revealed their acknowledgement of this reality based on patient care delivery experiences. In contrast, nurse manager participants shared the fact that nursing unit staff typically did not attend meetings that were posted by hospital management and leadership to engage the input of staff regarding quality initiatives.

While staff reported they realized the need internally for excellent teamwork across units and departments, there appeared to be a disconnect between the desire of hospital

Published by Sciedu Press leadership and management to enact QIs, and the willingness of hospital unit staff to follow their administrative lead. A disconnect between leadership and staff has been reported to be associated with unhealthy work environment characteristics in a hospital setting, and/or hospital unit staff perceptions of non-authentic leadership practices. ${ }^{[15,16,26]}$

\subsubsection{Vitality}

A long-time nurse employee stated, "You know, morale, this is the worst it's been in years"; another nurse noted "We need incentives for nurses and other staff to pick up extra shifts, and for good attendance; we used to have this, but we don't anymore." This belief was also shared by five other nursing unit staff employees during five different focus groups. A nursing assistant further remarked: "What makes you think any of this we are telling you will change for us? I'll bet they won't listen to us and nothing will change." This particular statement revealed a sentiment echoed by four other employees during four different focus groups. On the other hand, a department manager observed: "We try to keep things upbeat and do nice things for staff."

Evidence-based standards for a healthy work environment promote skilled communication and true collaboration, so that there is a clear and meaningful connection to support open communication and active listening between administrators and staff in healthcare settings. ${ }^{[1,3,15,16,26]}$ In this case, narrative data revealed participants' concerns underscoring a basic need to actively listen to each other to discern better ways to communicate across employee groups, in efforts to enhance morale, vitality and interconnectedness of management and staff.

\subsubsection{Authentic leadership}

Several nurses shared frequently-heard sentiments regarding the managers of the nursing units: "They need to ask us, 'What can I do?' when it's busy"; "There is little to no visibility of managers on the floor"; "Many managers do not know enough to work the floor, or to help you when you need it"; and "There is an extreme business orientation on the part of management; once we had to charge a family $\$ 5.00$ for a guest tray, they did not have a lot of money, it was embarrassing." A department manager framed her relationship with her staff: "My staff know what I expect, it's my way or the highway." 
Being able to "walk the talk" as a manager has been reported to go a long way in earning the respect and cooperation of healthcare employees. ${ }^{[15,16]}$ In this case, healthcare administrators may not have been provided the opportunity to learn about important aspects necessary to create a healthy work environment, and/or may not have been introduced to the principles of authentic leadership. As these narratives reveal, habits of thinking and communication may be developed by an administrator that actually undermine a healthy work environment, ultimately promoting discord, low morale and a lack of vitality among employees. ${ }^{[15,16]}$ Low morale contributes to moral distress and higher turnover among hospital unit employees. ${ }^{[15,16]}$

\subsubsection{Safety/Reliability}

A hospital administrator shared her thoughts about safety and hospital processes, "We have things falling through the cracks sometimes; I'm just waiting for something really bad to happen"; Regarding patient safety awareness in general, a unit secretary noted that "We all try to help each other when it comes to safety on the units where I work - the patient comes first, and I try to watch out for them." Increased cross-training of staff to address enhancement of clinical nursing skills on different units was also stressed in several groups. As a staff nurse explained, "We are doing some, but we need more cross-training to reach a knowledge comfort level, so that if we are short [staffed] and are moved to a different unit, we will know what we are doing."

Clear, open communication is key to positive, error-free patient outcomes in any healthcare setting. ${ }^{[1,15,16,26]}$ However, the narratives reveal that the need to maintain patient safety is perceived to be an ongoing issue by some hospital administrators and nursing unit staff. In addition, it has been frequently observed that rural nurses need to be trained as highly skilled generalists who receive regular review of both common and uncommon disease management topics via periodic, easily accessible continuing education. ${ }^{[3,10,11,25]}$ "Floating" to different units and/or taking on new responsibilities in nursing management, even in the smaller, low volume rural hospital setting, can seem daunting when the care provider has little to no experience in a particular area of expertise. ${ }^{[10,11,25]}$

\subsubsection{Value-Added care processes}

A hospital administrator discussed a nursing unit rounding experience: "It is when I walk into a patient's room, and I ask how their care has been with nursing staff, and they tell me 'Oh, she has been so busy'; then I know they have not been in the room much during that day"; A manager related her stance on valueadded care: "You know what I would tell them [staff] - sometimes it's the smallest thing that they [the patient] will remember, if you brought them a pillow, or answered their call light right away and helped them to the bathroom." Another nurse administrator, when discussing the current economic outlook, advocated the idea of emphasizing the hospital's financial stability with employees: "I don't care what they think, they need to realize the nice things we do for you, and that we are financially stable."

A hospital administrator explained that she and the unit managers try to round on nursing units once a month to evaluate important aspects of patient care. In contrast, some experts suggest rounding more frequently (weekly or even daily) depending on time constraints, so that staff perceives administrators as highly accessible to discuss patient care issues. ${ }^{[15]}$

Healthcare team efforts to improve patient satisfaction and patient-provider communication have been reported to enhance patient health outcomes. ${ }^{[1,15,16]}$ On the other hand, a hospital administrator who wished to emphasize the financial stability of the hospital to staff demonstrated what has been reported as a dysfunctional response to conflict with employees. ${ }^{[15,16]}$ Utilizing verbally aggressive, uncaring expressions such as "I don't care what they think" decreases morale and increases stress, and therefore turnover among staff. $^{[15,16]}$

\subsection{Consideration of the research question}

The purpose of this study was to explore perceptions of work environment characteristics across employee groups in a rural hospital to determine if authentic leadership and management practices were perceived to be actualized in the organization. Creating a healthy work environment through authentic leadership practices is critical to sustaining care QIs and patient safety. Therefore, the exploratory research question for this study inquired "How might hospital leadership, management and unit/departmental staff in a rural hospital respond to a study regarding the key healthy work environment characteristics reported to be necessary to support robust potential for successful QIs?" The qualitative and quantitative results of this study point to a perceived lack of vitality among clinical and ancillary staff compared to the hospital's administrative staff. However, clinical and ancillary staff still reported that they would speak up if there was a patient safety concern, which is a credit to management's efforts to promote patient safety. 


\section{Discussion}

The vitality of a workforce is important because it reflects the degree to which there is a collective perception that each person, regardless of position, is important, valued and collaboratively involved in shared decision-making regarding key work processes that drive the quality of outcomes in an organization. ${ }^{[15,16,18]}$ In addition, mutual trust and collegial, open communication are paramount to achieving successful outcomes in a team-driven healthcare work environment. ${ }^{[15,16,18,26]}$ To encourage balanced consideration of study data, the study team supported reflective discussion of strengths and areas for growth with hospital leadership, management and staff upon completion of study data collection and analysis.

Key conceptual areas highly relevant to successful QI implementation were perceived to be present across the workforce based on data collection, including positive perceptions of employees' caring orientation toward patients and families, the open reporting of any patient safety concerns, as well as staff members' desire and efforts to engage in patient-centered care. These skills and attitudes should support higher levels of vitality and teamwork to provide the foundation for meaningful staff-driven innovations. ${ }^{[1,15,16]}$ In addition to selected positive perceptions of the work environment revealed in the data, the reported differences in 1) management and staff perceptions of employee morale, 2) employees' perceptions of a lack of authentic leader behaviors among nurse administrators, and 3) statistically significant differences in levels of vitality across hospital employees, also needed to be considered.

\subsection{Transactional v. authentic, transformational leadership}

During a discussion of study results regarding healthy work environment characteristics, hospital administrative team members were perplexed regarding the data-based outcomes for hospital staff compared to administrators' results. The administrators stated that they engaged in staff reward activities such as pizza parties or incentives for working an extra shift, but that staff did not seem to appreciate, or respond to, these efforts. In response, study team members observed that transactional leader behaviors typically emphasize and reinforce superficial exchanges with employees, reflecting a task-oriented "only give something to get something" mentality. ${ }^{[27]}$

In contrast, experts tell us that authentic, transformational leaders move beyond a directive, hierarchical leadership model and work to inspire employees. ${ }^{[15,16,18,27]}$ Authentic leaders provide an organizational vision by promoting the professional values of trust and respect to sustain healthy work relationships and two-way communication. ${ }^{[15,16,19,27]}$ With these efforts, authentic leaders are in a better position to sustain truly collaborative work team in- novation based on current evidence. ${ }^{[15,16,19,27]}$ Positive perceptions of leadership in a healthcare setting have also been associated with willingness to implement evidence-based QIs, ${ }^{[15,16,18,19]}$ and patient safety practices. ${ }^{[18,24,25]}$

\subsection{Lessons learned}

To capture lessons learned, the study team posits that there are important clues to the issues between hospital administrators and staff that are relevant to care providers' capacity to enact successful QI-based changes in the hospital. Evidence of important lessons derived from this study include:

- Staff not wanting to attend nursing units' administrative meetings when they are invited to attend and provide input.

- Perceptions repeatedly mentioned by nursing unit staff regarding “... they won't listen to us and nothing will change”.

- The hospital administrators' perplexed state regarding their perception that hospital leadership and management strived to consistently provide reward and recognition to departmental/unit staff based on positive outcomes.

Key sub-themes emerging from narrative data, "disconnect between leadership and staff" and "a basic need to actively listen to each other", were repeatedly revealed in 4/5 thematic categories. Based on these two sub-themes, it becomes important to alert both management and staff regarding an important caveat concerning desired behavioral change. As a wise chief nursing officer once stated during a system-wide patient safety study, "Culture eats strategy for lunch every day!"[24] Promoting simple and positive behavioral change incurs no cost, except the time it takes to actively listen to each other, reflect and engage in a new, healthier and more functional behavior at work. ${ }^{[15,26]}$ As a follow-up to this study, the participating rural hospital administrators recently decided to become involved in a multisite rural health services research study co-led by the authors that will involve measures to promote improvements in quality of care and healthy work environment initiatives in a group of U.S. rural critical access hospitals (November, 2014).

\subsection{Limitations}

While the authors made every effort to conduct this study in a comprehensive manner utilizing mixed methods to assess both administrator and staff perspectives regarding the hospital work environment, the study involved one Midwestern U.S. rural hospital. Therefore, these results may not be generalizable to the larger population of rural hospitals globally. However, the authors hope that this study helps to illustrate and highlight key behaviors important to the establishment of a healthy work environment through application 
of authentic leadership principles. These principles may be applied regardless of the locale of the hospital administrator who decides to proactively engage themselves and their hospital staff in positive, relational growth and development.

\subsection{Implications for hospital administrators and managers}

If hospital leaders and managers desire to thrive in the current quality-driven healthcare environment, a sociobehavioral assessment may reveal that work is needed to remedy instances of ineffective employer-employee relationships in their organization. When purposefully implemented, the five principles of authentic leadership can empower unit and departmental employees to sustain open, respectful communication and work relationships across the organization. ${ }^{[16]}$ The principles of authentic leadership include skilled communication, true collaboration, shared decision-making, appropriate staffing, and meaningful recognition. ${ }^{[16]}$

In particular, authentic leaders “... must be skilled communicators, team builders, agents for positive change, committed to service, results-oriented, and role models for collaborative practice". ${ }^{[16]}$ In a healthy work environment, leadership and management work with staff to embrace selfimprovement, and strive to maintain collegial work relationships based on trust. If dysfunction creeps into working relationships, an administrator may take on intimidating, directive behaviors that reinforce mistrust, and pro- mote "deficient interpersonal relationships, chronic stress, and dissatisfaction" among employees. ${ }^{[16]}$ In addition, the authors suggest that authentic leadership requires empowerment of a mutually beneficial and trustworthy "two-way street", wherein hospital staff would need to learn to be open and responsive to leadership and management's future efforts to promote a healthy work environment. With this imperative, it is suggested that the two-way communications and desirable care delivery accountabilities would be defined based on the collaboratively-driven TCAB principles moving forward. ${ }^{[15,16]}$

The qualitative and quantitative results of this study point to a perceived lack of vitality among clinical and ancillary staff compared to the hospital's administrative staff. Moreover, there was a perceived lack of mutual trust and a reported disconnect between hospital administrators and staff due to a lack of collegial two-way communication between hospital administrators/managers and clinical and ancillary staff. Therefore, to address healthy work environment issues as they arise in an organization, the authors recommend that health services research projects in the hospital work environment routinely include the utilization of socio-behavioral instruments to measure the potential for human interpersonal and/or team-based barriers versus facilitators to QI implementation. The importance of mutual trust and respectful two-way communication across hospital unit staff, management and leadership teams reflects the power of intentional authentic leadership, and is paramount to successful QI implementation in any healthcare organization. ${ }^{[15,16,18,26]}$

\section{References}

[1] Centers for Medicare and Medicaid (CMS). Accountable Care Organization: 2012 Program Analysis: Quality Performance Standards Narrative Measure Specifications: Final Report. Baltimore, MD: Office of Clinical Standards \& Quality. 2012. Available from: http://www.cms.gov/Medicare/Medicare-Fee-for-Servi ce-Payment/sharedsavingsprogram/Downloads/ACO_Qual ityMeasures.pdf . Accessed February 25, 2014.

[2] National Strategic Framework for Remote and Rural Health (NSFRRH), the Commonwealth of Australia, 2012. Available from: http://www.ruralheal thaustralia.gov.au/internet/r ha/publishing.nsf/Content/EBD8D28B517296A3CA2579FF 000350C6/ protect \T1 textdollarFile/NationalStrate gicFramework.pdf. Accessed April 3, 2014.

[3] World Health Organization (WHO). Global Policy Recommendations on increasing access to health workers in remote and rural areas through improved retention. 2010. Available from: http://whqlibdoc.who.int/publications/2010/97 89241564014_eng.pdf. Accessed April 3, 2014.

[4] MacKinney AC, Mueller KJ, McBride TD. The March to Accountable Care Organizations-How Will Rural Fare? Journal of Rural Health. 2011; 27(1): 131-137. PMid: 21204980. http://dx.doi $. \mathrm{org} / 10.1111 / \mathrm{j} .1748-0361.2010 .00350 . \mathrm{x}$

[5] MacVicar R, Nicoll P. NHS Education for Scotland: Supporting Remote and Rural Healthcare. NES Board Paper. August 2013. Available from: http://www.rrheal.scot.nhs.uk/media/18525
$2 /$ remote $\% 20$ and $\% 20$ rural $\% 20$ healthcare $\% 20$ updated.pdf . Accessed April 4, 2014.

[6] Iowa Department of Public Health (IDPH). "2012 Iowa Small Hospital Improvement Program (SHIP) Briefing and Survey Report". 2012. Available from: http://www.ruralcenter.org/sites/ default/files/ship/coordinator-ta-webinars $/ 2012 \% 2$ OIA $\% 20$ SHIP $\% 20$ Briefing $\% 20$ and $\% 20$ Survey $\% 20$ Report.pdf . Accessed February 12, 2014.

[7] Minnesota Rural Health Cooperative (MRHC). "MRHC: Minnesota Community Measurements". 2013. Available from: http://www. mrhc.net/services.php. Accessed February 10, 2014.

[8] Montana Rural Health Care Performance Improvement Network (MRHCPIN). "Medicare Critical Access Hospital Conditions of Participation". 2013. Available from: http://www.mtpin.org. Accessed March 3, 2014.

[9] Rural Wisconsin Health Cooperative (RWHC). "RWHC Quality Indicators Program". 2013. Available from: http://www.rwhc.com/Services/QualityPrograms/RW HCQualityIndicatorsProgram.aspx. Accessed February 10, 2014.

[10] Kenny A, Duckett S. Educating for rural nursing practice. Journal of Advanced Nursing. 2003; 44(6): 613-622. http://dx.doi.org/1 $0.1046 / j .0309-2402.2003 .02851 . x$

[11] Macleod MLP, Lindsey E, Ulrich CH, et al. The development of a practice-driven, reality-based program for rural acute care registered nurses. The Journal of Continuing Education in Nursing. 2008; 
39(7): 298-304. http://dx.doi.org/10.3928/00220124-200 80701-03

[12] Munroe D, Duffy P, Fisher C. Fostering evidence-based practice in a rural community hospital. Journal of Nursing Administration. 2006; 36(11): 510-512. PMid: 17099434. http://dx.doi.org/10.10 97/00005110-200611000-00004

[13] Fairchild RM. Hold That Tiger! A Collaborative Service Learning Academy-Practice Partnership in Information Technology with Rural Healthcare Facilities. Nurse Educator. 2002; 37(3): 108-114. PMid: 22513769. http://dx.doi.org/10.1097/NNE.0b013e3 $18250415 \mathrm{~b}$

[14] Fairchild RM, Everly M, Bauer R, et al. Rural Nurses' Continuing Education Needs: A U.S. Multi-Site Survey Reveals Challenges and Opportunities. Journal of Nurse Education and Practice. 2012; 3(5): 45-55.

[15] Institute for Healthcare Improvement (IHI). Transforming care at the bedside. 2010. Available from: http://www.ihi.org/offerings/Initiatives/PastSt rategicInitiatives/TCAB/Pages/default.aspx. Accessed June 26, 2014.

[16] American Association of Critical Care Nurses (AACN). Standards for establishing and sustaining healthy work environment. 2005 Available from: http://www.aacn.org/wd/hwe/docs/hwest andards . pdf . Accessed March 10, 2014.

[17] Centers for Medicare and Medicaid Services (CMS). Medicare "Accountable Care Organizations: Shared Savings Program". Washington, DC: CMS. 2012. Available from: http://www.cms.gov/Medicare/Medicare-Fee-for-Servi ce-Payment/sharedsavingsprogram/index.html?redirec t=/sharedsavingsprogram/. Accessed December 20, 2012.

[18] Institute of Medicine (IOM). The Future of Nursing: Leading Change, Advancing Health. National Academies of Science, Washington, DC. 2010. Available from: http://www.iom.edu/Reports/2010/The-future-of-n ursing-leading-change-advancing-health.aspx . Accessed February 10, 2014.
[19] Needleman J, Parkerton PH, Pearson ML, et al. Impacts on the Learning Community Hospitals of Transforming Care at the Bedside. American Journal of Nursing. 2009; 109(11): 65-69.

[20] Upenieks V, Needleman J, Soban LM, et al. The relationship between the volume and type of transforming care at the bedside innovations and changes in nurse vitality. Journal of Nursing Administration. 2008; 38(9): pp386-394. PMid: 18791422. http: //dx.doi.org/10.1097/01.NNA.0000323959.52415.86

[21] Caracelli VJ, Greene JC. "Crafting mixed-method evaluation design." In J. C. Greene and V. J. Caracelli (eds.), Advances in mixedmethod evaluation: The challenges and benefits of integrating diverse paradigms. New Directions for Program Evaluation. San Francisco, CA: Jossey-Bass; 1997(74). pp19-32.

[22] IBM Corp. IBM SPSS Statistics for Windows, Version 20.0. Armonk, NY: IBM Corp; Released 2011.

[23] Lincoln YS, Guba EG. Naturalistic inquiry. Newbury Park, CA: Sage Publications; 1985.

[24] Moody RC, Pesut DJ. Harrington CF. Creating Safety Culture on Nursing Units: Human Performance and Organizational System Factors That May Make a Difference, Journal of Patient Safety. 2006; 2(4): 198-206. http://dx.doi.org/10.1097/01.jps. 0000242978.40424 .24

[25] McCoy C. Professional development in rural nursing: Challenges and opportunities. The Journal of Continuing Education in Nursing. 2009; 40(3): 128-131. http://dx.doi.org/10.3928/0022012 4-20090301-08

[26] Weick KE. The reduction of medical errors through mindful interdependence. In: Rosenthal MM, Sutlcliffe KM, eds. Medical Error: What Do We Know? What Do We Do? San Francisco, CA: John Wiley and Sons, Inc; 2002. pp84-100.

[27] Aaron GA. Transformational and transactional leadership: Association with attitudes toward evidence-based practice. Psychiatric Services. 2006; 57(8): 1162-1169. http://dx.doi.org/10.1176/p s.2006.57.8.1162 